CARE OF THE WILDERNESS ATHLETE

\title{
Wilderness Preparticipation Evaluation and Considerations for Special Populations
}

\author{
Elizabeth Joy, MD, MPH; Karin Van Baak, MD; Katherine L. Dec, MD; Barbara Semakula, MD; \\ Ashlea D. Cardin, OTDs, OTR/L, BCP; Jay Lemery, MD; George C. Wortley, MD; Michael Yaron, MD; \\ Christopher Madden, MD
}

From Clinical Outcomes Research, Intermountain Healthcare, Salt Lake City, Utah (Dr Joy); the Department of Family Medicine, University of Colorado, Denver, Colorado (Dr Van Baak); CJW Sports Medicine, Richmond, Virginia (Dr Dec); the Anne Arundel Medical Center, Orthopedic and Sports Medicine Center, Annapolis, Maryland (Dr Semakula); Missouri State University, Springfield, Missouri (Dr Cardin); the Department of Emergency Medicine, University of Colorado, Aurora, Colorado (Drs Lemery and Yaron); the Big Island Family Medicine Center, Lynchburg, Virginia (Dr Wortley); and Longs Peak Sports Medicine, Longmont, Colorado (Dr Madden).

\begin{abstract}
Children, older adults, disabled and special needs athletes, and female athletes who participate in outdoor and wilderness sports and activities each face unique risks. For children and adolescents traveling to high altitude, the preparticipation physical evaluation should focus on risk assessment, prevention strategies, early recognition of altitude-related symptoms, management plans, and appropriate follow-up. As the risk and prevalence of chronic disease increases with age, both older patients and providers need to be aware of disease and medication-specific risks relative to wilderness sport and activity participation. Disabled and special needs athletes benefit from careful pre-event planning for the potential medical issues and equipment modifications that may affect their health in wilderness environments. Issues that demand special consideration for female adventurers include pregnancy, contraceptive use, menses, and ferritin levels at altitude. A careful preparticipation evaluation that factors in unique, population- specific risks will help special populations stay healthy and safe on wilderness adventures. The PubMed and SportDiscus databases were searched in 2014 using both MeSH terms and text words and include peer-reviewed English language articles from 1977 to 2014. Additional information was accessed from Web-based sources to produce this narrative review on preparticipation evaluation for special populations undertaking wilderness adventures. Key words include children, adolescent, pediatric, seniors, elderly, disabled, special needs, female, athlete, preparticipiation examination, wilderness medicine, and sports.
\end{abstract}

Key words: preparticipation evaluation, pediatrics, altitude, older adult, disabled and special needs athlete, pregnancy

\section{Introduction}

Preparticipation physical evaluations (PPE) are a regular, and typically required, component of screening and evaluation before participation in organized sports for younger athletes (eg, junior high, high school, and college). A standardized approach to the PPE (Fourth

The authors report no conflicts of interest.

This article appears in a "Care of the Wilderness and Adventure Athlete" special issue, jointly published by Clinical Journal of Sport Medicine and Wilderness \& Environmental Medicine.

Corresponding Author: Elizabeth Joy, MD, MPH, Clinical Outcomes Research, Intermountain Healthcare, 36 South State St, 16th Floor, Salt Lake City, UT 84111 (e-mail: liz.joy@imail.org).
Edition PPE Monograph) was developed and endorsed by 6 major medical societies-the American College of Sports Medicine, the American Medical Society for Sports Medicine, the American Academy of Family Physicians, the American Academy of Pediatrics, the American Orthopedic Society for Sports Medicine, and the American Osteopathic Academy for Sports Medicine. ${ }^{1}$ The purpose of the PPE is to identify health conditions that may put the athlete at risk for illness or injury as a result of their participation in sport.

Millions of American youth undergo a PPE as a result of organized sport participation each year; however, athletes who participate in sports and activities that are not school based are likely to not undergo such 
screening. As youth participation in "nontraditional" adventure and wilderness sports and activities such as rock-climbing, mountaineering, downhill mountain bike riding, and free skiing increases, physicians should be knowledgeable regarding the risks associated with those activities, and guidelines regarding screening and clearance need to be established.

Individuals of all ages enjoy sports and activities in the wilderness. Middle-aged and senior athletes and adventurers likely outnumber youth in outdoor sports participation. Pregnant women are adjusting climbing harnesses to continue rock climbing during pregnancy. Adults of all ages are scaling mountains, careening down mountain bike trails, and skiing in both competitive and noncompetitive settings. When one considers that chronic diseases, such as hypertension, diabetes, and heart disease, increase in incidence with age, then these are the individuals to screen before participation in wilderness sports and activities.

It is important to bear in mind that there are few randomized control trials and systematic reviews examining the relationship between environmental exposures and risk of injury, illness, or death among the special populations of athletes included in this review. However, authors attempted to comprehensively review and summarize the published literature with the objective of providing a broad overview of risks and considerations to assist Sports Medicine and Primary Care physicians in evaluating athletes considering participation in wilderness adventures. Understanding these unique risks, as well as their interaction with age, chronic disease, disabilities, and conditions such as pregnancy, will help health care providers better care and prepare their patients for safe participation.

\section{Pediatric Altitude Travel (Yaron)}

\section{OVERVIEW}

Altitude illness ranges from the relatively benign acute mountain sickness (AMS) to life-threatening high-altitude cerebral edema (HACE) and high-altitude pulmonary edema (HAPE). Children can develop these illnesses when traveling to high-altitude locations particularly after rapid ascent, and clinicians may be asked to perform preparticipation evaluations to assess individual risks and provide altitude illness prevention and treatment strategies.

\section{PHYSIOLOGY}

Acute hypoxia initiates physiologic responses in children associated with development of altitude illness. While most of these responses are similar to adults, young children have significant differences. The circulatory transition from fetal to postfetal life deserves special mention. Fetal circulation is characterized by low fetal $\mathrm{Po}_{2}$ and minimal pulmonary blood flow secondary to high pulmonary vasoconstriction and vascular resistance. Right to left shunting across the foramen ovale and ductus arteriosus diverts blood around the lungs and toward the placenta. At birth, pulmonary vascular resistance falls, blood flow increases immediately, and a cardiopulmonary transition begins that gradually closes shunts and remodels endothelial and muscular structures. Among infants at sea level, this transition is generally complete by 4 to 6 weeks. ${ }^{2}$ Ascent to altitude among infants younger than 4 to 6 weeks may induce a return to fetal circulation patterns without the benefit of a placenta causing sudden severe hypoxemia. Infants with a history of premature birth, supplemental oxygen use, or living at altitude are particularly at risk. ${ }^{3}$

Normal newborn infants have periodic breathing patterns that decrease over the first 6 months. ${ }^{4}$ This periodicity increases during both sleep and with altitude exposure resulting in recurrent oxygen desaturation. As such, ascent among premature babies should be delayed until they mature because severe periodicity and desaturation may occur at altitude. ${ }^{5}$

\section{EPIDEMIOLOGY}

Altitude illness is common with rapid ascent to moderate altitude (2500-3500 m; 8000-11 $500 \mathrm{ft}$ ), although most serious cases (HAPE and HACE) are seen at very high altitude (3500-5500 m; 11 500-18 $000 \mathrm{ft})$. Extreme high altitude (above $5500 \mathrm{~m}$; $\sim 18000 \mathrm{ft}$ ) poses the greatest risk for severe illness and is no place for young children.

Most evidence suggests that the incidence of AMS in children is similar to adults. ${ }^{6-13}$ Approximately $25 \%$ of all visitors to moderate altitudes develop AMS symptoms. ${ }^{14}$ The high-altitude pulmonary edema is much less common: $1.5 \%$ of children at $4500 \mathrm{~m}^{6}$ and $0.2 \%$ to $15 \%$ of adults depending on altitude and ascent rate. Children living at high altitude develop reentry HAPE much more frequently $(6 \%-17 \%)$ than adults. ${ }^{15,16}$ The HACE in children is rare with only 5 cases reported in adolescents. ${ }^{17,18}$ The recent trend of young climbers on Mt. Everest may result in more HACE in this age group.

With millions of families traveling to high altitude, ${ }^{19}$ AMS is a significant public health issue, demanding improved education of the populations at risk and careful preparticipation evaluation by the clinicians who care for them. ${ }^{20}$ 


\section{RISK FACTORS}

Rapid ascent rates (often by airline or automobile travel), higher sleeping altitude, individual susceptibility, duration of stay, and previous altitude exposure are primary risk factors. ${ }^{21-24}$ Not all children with histories of AMS or HAPE will experience symptoms with repeated ascent, yet many have recurrent susceptibility. ${ }^{11}$

Children with underlying medical conditions causing hypoxia sensitivity or pulmonary hypertension have an increased risk for severe altitude illness with ascent. These include incomplete postnatal circulatory transition, ${ }^{3}$ viral respiratory infection, ${ }^{25}$ atrial or ventricular septal defects, patent foramen ovale and ductus arteriosus, pulmonary vein stenosis, absence of a pulmonary artery, Down syndrome, ${ }^{26}$ and obstructive sleep apnea. ${ }^{27}$ After any significant altitude- related illness (especially HAPE) in a young child or occurrence of illness at lower-than-expected altitudes for all age groups, evaluation for occult structural cardiopulmonary abnormalities should be considered. ${ }^{27,28}$ Children with sickle cell disease should avoid ascent above $1800 \mathrm{~m}$ without supplemental oxygen because a crisis may result. $^{29,30}$

\section{ENVIRONMENTAL CONSIDERATIONS}

The extremes of solar radiation and temperature at altitude mandate adequate UV light protection and thermal insulation particularly for inactive children who are being carried by adults. Since descent is critical for treatment of severe altitude illness, locations with difficult descent conditions should be avoided. This is especially true for settings where further ascent is necessary before descent is possible. Therefore, travel to locations where evacuation or medical support may be unavailable is probably best done without children.

\section{CLINICAL PRESENTATION}

After recent altitude gain, AMS symptoms can develop within a few hours and generally reach maximum severity in 1 to 2 days. In adults, these include headache and at least one of the following: anorexia, nausea, vomiting, weakness, fatigue, dizziness, lightheadedness, or sleeping difficulty. ${ }^{31}$ These include headache and at least one of the following: anorexia, nausea, vomiting, weakness, fatigue, dizziness, lightheadedness, or sleeping difficulty. These adult criteria for AMS may be used in older children who can verbally express headache or hunger. In children with early language skills, headache and appetite questions need age-adjusted language to ensure comprehension. Asking if their "head hurts" for headache and if they are "hungry" to assess appetite can be effective. ${ }^{32}$ Among infants and preverbal children, AMS is assessed using nonverbal criteria. Acute mountain sickness is manifested by increased fussiness (headache equivalent), decreased playfulness, decreased appetite, and sleep disturbance. Often all these symptoms are present. Fussiness is irritability not easily explained by a cause, such as tiredness or hunger and includes crying, restlessness, or muscular tension. Vomiting may occur and markedly decreased playfulness and sleep may be seen. Although parents can usually recognize these behavioral alterations, a scoring system may be used to help parents identify AMS in preverbal children (Figure 1). ${ }^{7,20}$

Physical signs differentiate mild from severe altitude illness. There are no diagnostic physical signs in mild AMS. Signs of neurologic dysfunction are evidence of HACE. These include ataxia and altered mental status, leading to progressive decrease in responsiveness, coma, and death. Similarly, although dyspnea on exertion is universal at high altitudes, dyspnea at rest should be recognized as an early indicator of HAPE. This occurs in 2 different settings among children. Ascent HAPE may occur in a child living at lower altitude and traveling high. Reentry HAPE affects children living at high altitude who develop symptoms when returning home after travel to lower altitudes. Agitation, productive cough, cyanosis, and tachycardia may be seen with HAPE and is often preceded by AMS. Mild to moderate cases generally resolve without difficulty; however, if unrecognized and untreated, morbidity and death may occur rapidly, especially when infection or cardiac conditions complicate the illness. ${ }^{18,25}$

\section{MANAGEMENT AND PREVENTION}

In children, the management of altitude illness must include ending further ascent. Mild cases of AMS may be treated without descent if careful observation is available. In these cases, staying at the current altitude and resting can enable further acclimatization allowing resolution of AMS among most children in 1 to 3 days. Acute mountain sickness that becomes worse or does not respond to maintenance of altitude, rest, and pharmacologic intervention mandates descent. Descending in a stepwise manner (500-1000 m) to the lowest altitude at which symptoms resolve may be the safest approach.

Recommendations for pharmacologic intervention of altitude illness in children are based on anecdotal experience and extrapolation from adult treatments (Table 1). ${ }^{24}$ Treatment of headache with ibuprofen or acetaminophen and nausea with ondansetron is beneficial for mild AMS and frequently sufficient. ${ }^{10}$ The use of acetazolamide in children when conservative measures have failed is supported by anecdotal experience. ${ }^{18}$ Neurologic signs of ataxia or altered mentation must 
Fussiness is defined as a state of irritability that is not easily explained by a cause, such as tiredness, hunger, teething or pain from an injury. Fussy behavior may include crying. restlessness, or muscular tension. Please rate your child's typical fussy behavior during the last 24 hours without the benefit of your intervention.

AMOUNT OF UNEXPLAINED FUSSINESS

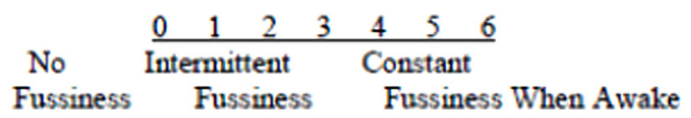

INTENSITY OF FUSSINESS

\begin{tabular}{|c|c|c|}
\hline No & $\frac{0112}{\text { Moderate }}$ & $\begin{array}{ccc}4 \quad 5 \quad 6 \\
\text { Severe }\end{array}$ \\
\hline Fussiness & Fussiness & Fussiness When Awake \\
\hline
\end{tabular}

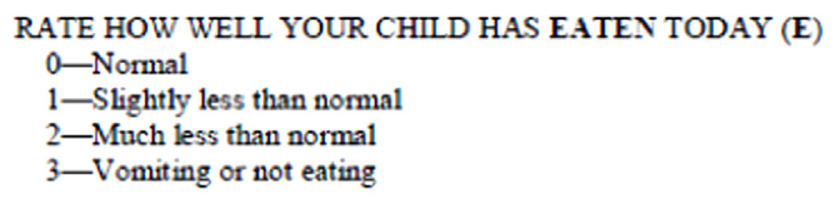

The CLIS must be $\geq 7$ with both the FS $\geq 4$ and $\mathrm{E}+\mathrm{P}+\mathrm{S} \geq 3$ to confirm acute mountain sickness.

Figure 1. Children's Lake Louise Score. ${ }^{7}$

be treated urgently for HACE with descent, oxygen, and dexamethasone.

For children with severe HAPE, descent with oxygen is the treatment of choice. Mild cases of HAPE may be treated with oxygen and bed rest without descent when medical observation is available. ${ }^{33}$ Oxygen is administered for 2 to 3 days to maintain an arterial oxygen saturation of at least $90 \%$. At flow rates of 2 to 4 $\mathrm{L} / \mathrm{min}$ or less, children may be treated at home while avoiding physical exertion and exposure to cold. With mild HAPE, most children treated without descent resolve within 1 to 3 days of oxygen therapy. ${ }^{33}$ Pharmacotherapy for HAPE is rarely needed because oxygen and/or descent are so effective. Nifedipine and sildenafil may be used in emergency settings where oxygen and descent are not available.

The best way to prevent altitude illness is to allow acclimatization with slow ascent. Gradual ascent over 2 to 3 days to 2500 to $3000 \mathrm{~m}$ minimizes risk. Alternatively, the first night should not be spent higher than $2850 \mathrm{~m}$ followed by 2 to 3 nights without further ascent to higher sleeping altitudes. Subsequent ascent to higher sleeping altitudes should not exceed $500 \mathrm{~m}$ per night. One extra night of acclimatization (at the same sleeping altitude) should be taken for every additional $1500 \mathrm{~m}$ gained. ${ }^{24}$ Prophylactic medication may be considered for 
Table 1. Medications for treatment of altitude illness in children

\begin{tabular}{|c|c|c|}
\hline Medication & Indication & Dose and Route \\
\hline \multirow[t]{2}{*}{ Acetazolamide } & AMS prevention ${ }^{*}$ & $2.5 \mathrm{mg} / \mathrm{kg}$ PO every $12 \mathrm{~h}$; maximum $125 \mathrm{mg}$ per dose \\
\hline & AMS treatment & $2.5 \mathrm{mg} / \mathrm{kg}$ PO every $12 \mathrm{~h}$; maximum $250 \mathrm{mg}$ per dose \\
\hline \multirow[t]{2}{*}{ Dexamethasone } & AMS prevention & $0.15 \mathrm{mg} / \mathrm{kg} \mathrm{PO} / \mathrm{IM} / \mathrm{IV}$ every $6 \mathrm{~h}$; maximum $4 \mathrm{mg}$ per dose \\
\hline & AMS/HACE treatment & \\
\hline \multirow[t]{3}{*}{ Nifedipine } & HAPE treatment $(<60 \mathrm{~kg})^{\S}$ & $\begin{array}{l}0.5 \mathrm{mg} / \mathrm{kg} \text { PO every } 4-8 \mathrm{~h} \text {; } \\
\text { maximum } 20 \mathrm{mg} \text { per dose }\end{array}$ \\
\hline & HAPE treatment $(>60 \mathrm{~kg})$ & $\begin{array}{l}30 \mathrm{mg} \text { SR PO every } 12 \mathrm{~h} \text { or } \\
20 \mathrm{mg} \mathrm{SR} \text { PO every } 8 \mathrm{~h}\end{array}$ \\
\hline & Re-entry HAPE prevention & Same dose as HAPE treatment \\
\hline Sildenafil & $\mathrm{HAPE}^{\mathscr{I}}$ & $0.5 \mathrm{mg} / \mathrm{kg}$ per dose $\mathrm{PO}$ every $4-8 \mathrm{~h}$; maximum $50 \mathrm{mg}$ per dose every $8 \mathrm{~h}$ \\
\hline
\end{tabular}

IM, intramuscular; IV, intravenous; PO, by mouth; SR, sustained release.

* Not routinely recommended. Indicated with rapid ascent or known susceptibility. May be prepared as solution by compounding pharmacy.

Not recommended, adverse effects.

* Oxygen and descent are the treatment of choice for severe AMS. If acetazolamide is not tolerated, dexamethasone may be used. Descent, oxygen, and dexamethasone should be used in HACE.

\& If oxygen and descent unavailable. Liquid-filled capsules $(10 \mathrm{mg} / 0.34 \mathrm{~mL})$ can be punctured to obtain doses for children less than $20 \mathrm{~kg}$; sustained-release formulations cannot be broken for smaller doses.

${ }^{\mathbb{I}}$ If oxygen and descent unavailable or nifedipine not tolerated (hypotension). Food and Drug Administration warning against chronic use in children.

children with recurrent susceptibility and when rapid ascent is unavoidable. ${ }^{24}$ Although nifedipine is the primary agent used to prevent HAPE, acetazolamide may be used for prevention of AMS and has also been used to prevent reentry HAPE because it decreases hypoxic pulmonary vasoconstriction. ${ }^{34}$

\section{SUMMARY AND RECOMMENDATIONS}

The PPE for any child's journey to high altitude should focus on risk assessment, prevention strategies, early recognition of symptoms, management plans, and appropriate follow-up. A gradual ascent rate is the primary preventive measure. Risk assessment should also consider age, previous altitude illness, predisposing physiologic conditions, and access to medical care and evacuation resources. Travel to altitude with young infants is generally safe after 4 to 6 weeks when circulatory changes have occurred and most congenital abnormalities are detected. History and physical examination should identify high-risk predisposing conditions, including recent viral infections, cardiac malformations, and pulmonary hypertension. Low-risk children should not need medications for prophylaxis and should use gradual ascent instead.

Severe altitude illness may be prevented by early recognition of illness, cessation of further ascent, and early treatment. Early recognition requires education of family members regarding risk factors, and signs and symptoms. Descent is the mainstay of therapy for all forms of altitude illness. When descent is not feasible or illness is mild, other therapeutic options may be chosen.

Children with a history of altitude illness should followup with their physician to discuss both prevention strategies for future ascents and consideration of underlying cardiac conditions that may not be apparent on physical examination at low altitude.

\section{OLDER ADULTS (LEMERY AND WORTLEY)}

\section{Overview}

There is no common agreement as to when an individual becomes "old." 35 Many factors, including chronologic age, underlying illness, chronic disease, and functional status and capacity, enter into the definition. In some sports, such as competitive swimming, the Masters Division starts at age 25 years. Yet we all know 70year-old backpackers who outperform the average 25year-olds. As we age, we acquire more disease states because of the aging process, injuries, genetic predisposition, and lifestyle choices. Regular physical activity is one of the keys to successful aging. Most chronic disease states, including coronary disease, diabetes, hypertension, and osteoarthritis, become more common as we age. Medications used to treat these conditions can impact performance and safety in the wilderness, certain chronic conditions can impair function and acclimatization at altitude, and altitude can worsen or exacerbate diseases, such as chronic obstructive pulmonary disease (COPD) and coronary artery disease (CAD). 
Table 2. Selected physiologic changes associated with aging ${ }^{36}$

\begin{tabular}{ll}
\hline Cardiovascular & Decreased cardiac output \\
& Decrease in age-predicted maximal heart rate \\
Musculoskeletal & Decrease in VO2max Increased incidence of CAD \\
Neurologic/psychiatric & Decreased muscle mass Greater loss of type II (fast twitch) fibers \\
& Loss of muscle power is greater than the loss of endurance capacity \\
& Decline in cognitive function \\
& Slower reaction time due to slower central nervous system processing, \\
increasing the risk of falls or injury & Greater incidence of Parkinson disease and peripheral neuropathy \\
& Greater incidence of depression \\
& Greater incidence of sensory (hearing and vision) impairment \\
\hline
\end{tabular}

\section{PHYSIOLOGY}

Significant physiologic changes occur with normal aging. Regular exercise can lessen but does not prevent these changes. Selected physiologic changes in the cardiovascular, musculoskeletal, and neurologic/psychiatric systems relevant to wilderness participation in older adults are listed in Table 2.

\section{EPIDEMIOLOGY}

US census data from 2010 show there were 40267984 individuals aged older than 65 years, making up $13 \%$ of the population. This is a $15 \%$ increase from the 2000 census. As a percentage, the above 65-year-old group is growing faster than the general population. ${ }^{35}$ As the Baby Boomer Generation ages, we can expect more active older people in the wilderness.

\section{RISK FACTORS}

The incidence of most disease states increase with age. Over time, the mortality rate for all individuals engaging in wilderness sports will eventually be $100 \%$. However, certain chronic illnesses should make clinicians more vigilant for our patients participating in adventure and wilderness activities. Cardiovascular events in the wilderness setting are associated with increased morbidity and mortality because of longer transport time to delayed definitive medical care. Worsening chronic musculoskeletal conditions, such as degenerative joint disease, can be quite problematic not only for the older participant but also for other members of the wilderness expedition team. Unrecognized neurologic or psychiatric conditions in older participants can jeopardize individual and group safety.

In a survey of wilderness group leaders, the strongest predictors of successful completion of a group wilderness trip were (1) completion of a similar expedition and (2) the psychological profile of the individual. The best single predictor of a failed trip was difficulty with interpersonal relationships. ${ }^{37}$ In a survey of incidents in an organized group of older backpackers, the problems with the most serious potential for injury were related to behavioral aberrations because of previously unrecognized organic brain syndrome precipitated by the environmental and physical stress from the trip. ${ }^{38}$

\section{ENVIRONMENTAL CHALLENGES}

\section{Heat}

Many older adults are at increased risk of heat illness. Poor physical fitness, obesity, lack of heat acclimatization, and dehydration all decrease heat tolerance. Certain chronic medical conditions increase the risk for heatstroke, whereas increased temperature may exacerbate chronic medical conditions, such as diabetes (dehydration may increase the risk for hyperglycemia), cardiovascular disease (peripheral vascular disease and diminished cardiac output can limit heat dissipation and may lead to syncope or presyncopal symptoms), and medications, including diuretics, beta-blockers, anticholinergics and antipsychotics, may interfere with heat dissipation and adaptation. ${ }^{39}$

Individuals with a history of heat illness or at increased risk because of comorbidities should take steps to improve heat acclimatization. Daily, pre-trip exercise in the heat for short periods ( $\sim 1$ hour) over 10 to 14 days can acclimate individuals to heat. Individuals not properly acclimated to heat should gradually increase heat exposure over the first week of a trip by exerting most during cooler times of the day. Since dehydration predisposes to heat illness, it is important to remain hydrated using electrolyte-containing fluids. Monitoring urine frequency and targeting a light yellow urine can help individuals assess proper hydration in the backcountry.

\section{Cold}

Older adults are particularly vulnerable to cold; thermoregulatory mechanisms may be less responsive than in 
younger adults. ${ }^{40}$ Adaptation to the cold by peripheral vasoconstriction is diminished. Because of diminished muscle mass, heat generation from shivering is diminished. Medications, including beta-blockers and tranquilizers, may interfere with cold adaptation. Disease common in older adults that pose unique risks in cold may include angina and other cardiovascular disease (increased systemic vascular resistance and myocardial oxygen demand), peripheral arterial disease (increased risk for frostbite), neuromuscular disease (impaired shivering thermogenesis), and diabetes (hypoglycemia may impair thermogenesis; peripheral neuropathy may predispose to cold injury). ${ }^{39}$

\section{Altitude}

The effects of altitude exposure on older adults are less clear. Physiologic changes of aging, including thickening of the pulmonary alveolar-capillary membrane, diminished vital capacity, and reduced hypoxic ventilator drive, may worsen hypoxia at altitude. Ascent to altitude acutely increases sympathetic tone, heart rate, and blood pressure. Heart rate and blood pressure gradually decrease over several days at high altitude but remain higher than sea level baseline values for the duration of stay at high altitude. Despite the increase in sympathetic tone, most persons with mild to moderate cardiovascular disease do well after ascent to moderate altitudes of approximately $2500 \mathrm{~m}(8202 \mathrm{ft})$, although individuals with unstable angina, severe cardiomyopathy, or poorly controlled hypertension might not tolerate such changes. ${ }^{39,41-43}$ However, some studies on the incidence of AMS indicate that age older than 60 years may be protective. ${ }^{40}$ Many cardiovascular and pulmonary diseases can both impair acclimatization and become worse with ascent to altitude, especially COPD, CAD, congestive heart failure, and certain cardiomyopathies. For a more detailed discussion of the effects of altitude on chronic heart or lung disease, see Risk Stratification for Athletes and Adventurers in Altitude Environments: Recommendations for Preparticipation Evaluation, published in this supplement.

\section{APPROACH/CONDITIONS}

Under optimal conditions, older adults will seek medical evaluation by their primary care physician before undertaking vigorous activity in the wilderness. During the course of this PPE, medical conditions that may impact participation should be identified and appropriately evaluated. The following preparticipation recommendations, which focus more on seniors with chronic disease in traditional exercise and sport, unless otherwise noted, have been made by an expert panel representing several medical professional organizations. ${ }^{44}$ Please note that adventure and extreme environments, such as exposure to altitude and remote, technical terrain, may pose additional, unique environmentor activity- specific risks in seniors with chronic disease and should be appropriately considered during the PPE. Several of the more pertinent recommendations are summarized below.

\section{ATHEROSCLEROTIC CORONARY ARTERY DISEASE}

Individuals with documented CAD ( $>50 \%$ narrowing of coronary artery based on angiography) should not participate in high-intensity sports/activities without further consultation because of increased risk of myocardial infarction and sudden cardiac death. ${ }^{44}$

If participating in vigorous or strenuous activity, men and women with symptoms of, or established diagnoses of cardiovascular or metabolic disease (eg, diabetes, chronic kidney disease) should undergo evaluation by a primary care or sports medicine physician.

A combination of electrocardiogram (EKG), echocardiogram, and stress testing should be considered in atrisk individuals and participants aged 65 years or older participating in vigorous exercise even in the absence of risk factors or symptoms. Asymptomatic individuals are not immune from cardiac events. ${ }^{45}$

\section{HYPERTENSION}

Blood pressure rises acutely with exposure to altitude and remains above baseline with continued exposure. A small, portable wrist blood pressure cuff can be invaluable in wilderness settings. Patients should discuss a backup medication plan with their physicians if blood pressure becomes poorly controlled. Be aware of potential effects on performance and heat/cold tolerance due to antihypertensive medications. Those with prehypertension or stage 1 hypertension without end-organ damage may participate fully. Those with stage 2 hypertension ( $>160 />100 \mathrm{~mm} \mathrm{Hg}$ ) should be restricted from highresistance and high-intensity sports until their blood pressure is normalized.

\section{ARRHYTHMIAS}

Older patients with rate-controlled atrial fibrillation may safely participate in moderate-intensity activities. Patients who are taking anticoagulant medication (aside from aspirin) should be counseled about the risk of bleeding with contact or collision sports or in activities where there is a high risk of falling. Anyone experiencing arrhythmia symptoms that have not been appropriately evaluated or are unstable should not participate in 
wilderness and adventure activities. Supra-ventericular arrhythmias pose less risk than ventricular arrhythmias; however, if symptomatic, provocative stress testing should be considered. ${ }^{46}$ In these cases, counseling should be given on conservative vagal maneuvers or the use of medication for acute treatments.

\section{JOINT REPLACEMENT}

A recent review of the literature on physical activity following total joint arthroplasty concluded that the following activities were either "recommended" or "recommended with experience" for patients following knee and hip replacement: hiking, cycling, cross-country and downhill skiing. Rock climbing and "jogging" were not recommended. ${ }^{47}$ No mention was made of mountain biking. Many older athletes want to return to their previous activities. Joint manufacturers do not warrantee their devices for many common outdoor or wilderness activities. Physicians caring for patients who have undergone joint replacement surgery should encourage patients to participate in regular physical activity. There is no evidence that higher intensity and/or wilderness activities other than rock climbing, running, and possibly downhill skiing should be discouraged in knee or hip joint replacement patients who otherwise have the health, fitness and desire to participate

\section{CHRONIC OBSTRUCTIVE PULMONARY DISEASE}

Exercise tolerance and capacity should be determined for individuals with COPD participating in adventure and wilderness events that require exertion that exceeds baseline activities. Patients with mild disease category (FEV $1 \geq 80 \%$ predicted) generally do well with activities that pose similar demands to baseline. Moderate disease (FEV1 50\%-80\% predicted) poses greater risk, and cardiopulmonary exercise testing should be used to determine safe participation. Patients with severe $\left(\mathrm{FEV}_{1}\right.$ $30 \%-50 \%$ predicted) or very severe $\left(\mathrm{FEV}_{1} \leq 30 \%\right.$ predicted) disease, or those with carbon dioxide retention or right heart failure, should be advised against exceeding baseline activity tolerance and ascending to a higher altitude than their current residence. Such patients may, however, tolerate car or horse-led activities, such as safaris or fishing, that do not require much in the way of physical exertion. ${ }^{39}$

\section{TYPE 2 DIABETES}

Several issues need to be taken into consideration in type 2 diabetic patients before a wilderness or adventure trip. Factors such as dietary changes, food type and availability, exercise, and exertion exceeding baseline can all affect safe glycemic control. Insulin is at risk for freezing in the cold, so care should be taken for appropriate transport, such as in an inside pocket next to the skin or beneath insulation. Diabetic- related conditions and complications, such as CAD, peripheral and autonomic neuropathies, retinopathy, chronic kidney disease, increased risk for infection, and increased risk for heat and cold injury, should be carefully assessed and addressed in pre-event counseling. ${ }^{39}$

\section{RECOMMENDATIONS AND SUMMARY}

Older participants are encouraged to seek counsel from their primary care physician before undertaking vigorous or strenuous wilderness activities. Comorbid conditions and medications can impact the person's well-being and health, especially when encountering environmental extremes. Men and women of any age with symptoms of, or established diagnoses of, cardiovascular or metabolic disease (eg, diabetes, chronic kidney disease) should undergo comprehensive evaluation if participating in vigorous or strenuous activity, especially in remote environments.

\section{DISABLED AND SPECIAL NEEDS (DEC, SEMA- KULA, AND CARDIN)}

\section{Overview}

Participating in wilderness and outdoor adventures is becoming more available to individuals and professional athletes with physical impairment and special needs. ${ }^{48}$ These participants benefit from pre-event planning for the potential medical issues and equipment modifications that may affect health in these environments, and the limitation or disability of a single member may need to be compensated for by the strength and skill of the entire group and supporting parties. Medical professionals should review the individual's health history and complete a comprehensive physical assessment as part of the preparticipation planning. A helpful supplemental form for assessment and documentation of athletes with special needs can be found in the Preparticpiation Physical Evaluation, Fourth Edition: The Athlete with Special Needs Supplemental History Form. ${ }^{1}$ A key component to assessment is development of an emergency action plan (EAP) that considers excursion needs and known and potential medical issues specific to the athlete.

\section{HISTORY QUESTIONS}

The first important step is to evaluate the level of athlete independence. This includes determining assistive needs for mobility, activities of daily living, and fitness level. ${ }^{49}$ Energy expenditure for endurance of the event, terrain, and the weather can affect optimal choices of mobility. Options include a manual versus power wheelchair, walker, cane, crutches, adapted strollers, adapted vehicles/all-terrain 
vehicles or utility terrain vehicles and other assistive devices. Bowel and bladder function as well as hydration or medical intervention must be considered in any mobility device/ vehicle. In an athlete with limb deficiency, the prosthetic limb and terminal devices should be assessed and modified for the best functional level and skill required of the event. Fit, function, and tools needed for repair are all part of the plan.

Spinal cord injuries (SCIs), cerebral vascular accidents (CVAs), traumatic brain injuries (TBIs) and cerebral palsy have varying degrees of deficit and presentation. Comorbidities such as spasticity, clonus, autonomic dysreflexia (AD), thermoregulation, and medications should be assessed relative to the wilderness or adventure activity. Autonomic dysreflexia is a syndrome in which there is a sudden onset of increased blood pressure without tachycardia because of sympathetic system outflow disruption. It is more common in SCIs that involve the high thoracic and cervical spinal cord levels (T6 or above) and is a medical emergency. Decreased lower extremity or upper extremity joint mobility, whether from weakness, contracture, or joint replacements, may affect the functional skill required for wilderness events. Evaluate historical exacerbations and triggers for $\mathrm{AD}$ or spasticity, which may result in unsafe movement impairments. When evaluating muscular diseases, identify the type of condition, such as muscular dystrophy, and associated patterns of muscle involvement. Muscular dystrophies, such as myotonic muscular dystrophy, Duchenne, fascioscapulohumeral, have different muscle involvements and associated medical issues. Pulmonary function testing should be considered in anyone with neuromuscular impairment that threatens pulmonary and exercise capacity. Metabolic muscle disorders, such as glycogen storage disease, can also have an effect on training and exercise because of the specific enzyme deficiency. Muscle cramping, fatigue, and pain after exercise can occur. Risk of rhabdomyolysis with intense exercise may be managed in some athletes using a "second wind" strategy in which the fatiguing athlete lowers the training intensity; exercise can be increased again without recurrence of symptoms. ${ }^{50}$

Communication is paramount in wilderness adventures and events. Visual impairments, including monocular or binocular vision loss, impaired visual acuity, and problems with visual processing of information (cognitive component), may require partner assistance to navigate changing terrain. Hearing impairment may also affect the ability to monitor signs of danger, environmental hazards, and communication in a team event. Understanding and planning for the communication needs of athletes may include sign language, lip reading, hearing aid use, and function. Athletes with previous seizure activity should be in stable and seizure free, and medications and therapeutic levels should be appropriately assessed.

In athletes with bowel and/or bladder control dysfunction, especially for overnight trips, observing standardized fluid and nutrition replacement and utilizing safe, respectable, and preferred methods and equipment for management can help create a successful experience. Urinary catheters such as condom or indwelling catheters, or a clean intermittent selfcatheterization (CISC), will require sterile equipment to avoid risk of infection in wilderness. A successful bowel program will need to be developed and tested in training relative to the activity level and diet expectations of the trip. Medications should be assessed for potential side effects and effects with temperature extremes, hydration, and altitude exposure. Identifying comorbidities and how they may affect physical impairment is also important, including assessing the risk of deep venous thrombosis (DVT) or the use of anticoagulants (extra care to avoid trauma below level of sensation or SCI). Patients at risk of restrictive lung disease due to older age or the physical impairment, such as with certain muscular dystrophies, should be evaluated for lung capacity and function relative to the endurance or altitude demands of the event.

In athletes with bowel and/or bladder control dysfunction, especially for overnight outdoor adventure trips, understanding the equipment needed, preferred control and program plan, in addition to diet and activity needs, can help create a successful experience for an overnight event. Determine the best option for management, such as a condom, indwelling catheter, or a CISC, and ability to continue the current program in the planned event. Clean intermittent selfcatheterization will require sterile equipment to avoid risk of infection in wilderness. A successful bowel program will need to be developed and tested in training relative to the activity level and diet expectations of the trip. Medications should be assessed for potential side effects and effects with temperature extremes, hydration, and altitude exposure. Identifying comorbidities and how they may affect physical impairment is also important, such as assessing the risk of DVT or risk of anticoagulants (extra care to avoid trauma below level of sensation or SCI). Patients at risk of restrictive lung disease due to older age or the physical impairment, such as with certain muscular dystrophies, should be evaluated for lung capacity and function relative to the endurance or altitude demands of the event.

\section{EMERGENCY ACTION PLAN}

When creating an EAP, the effect of extremes in temperature, dehydration, ascent to altitude, potential 
excavation, and skin breakdown or trauma in insensate areas need to be considered in athletes with SCI or spasticity. ${ }^{51}$ Patients affected by AD in the field should immediately sit up straight or raise their head so they are looking straight ahead and should lower their legs below the level of the heart if possible. They should remain upright until blood pressure is back to normal. It is also important to loosen or take off any tight clothing or accessories-this may include braces, catheter tape, socks or stockings, shoes, and bandages. Affected individuals should drain urinary bladders with catheters if needed. Digital stimulation may be used to facilitate bowel emptying. Skin should be checked closely for pressure sores. A blood pressure cuff should be available to monitor blood pressure every 5 minutes until hemodynamic stability is achieved.

Several additional concerns in advising participation for an event include planning for monitoring urinary fluid loss (diuresis); understanding and planning for heat illness and managing heat extremes in at-risk athletes (SCI T8 or higher, or amputees with less body surface area to sweat naturally); monitoring insensate skin that may be at risk of burning (wind or sun); developing a hydration plan either provided by self, coaches, or caregivers; and finally, identifying factors such as an unsteady gait or cognitive impairment that may be confused with symptoms of heat exhaustion and heat stroke. $^{52}$

Seizures are common in many disabled athletes, and patients with cerebral origin motor dysfunction, such as cerebral palsy, TBI, and deficits from CVAs, may also have a seizure disorder. Dehydration, hypoglycemia, electrolyte imbalance, hyperventilation (eg, altitudeinduced), and physical and emotional stress may increase the possibility of seizure activity. ${ }^{53,54}$ Athletes with neurologic injury, sleep deprivation, exposure to temperature extremes, and overexertion have a lowered threshold for seizure activity. Exercise may increase the seizure threshold, so seizures that occur with physical activity imply poor control. ${ }^{53,55}$ Wilderness and adventure activities that involve a danger of falling and scuba diving are contraindicated for individuals with epilepsy.

Medication use is common in disabled athletes. Assess proper transport, storage needs, and backup emergency medications. Avoid benzodiazepine use when possible, especially at altitude due to suppression of acclimatization and hypoxia. Acetazolamide used to prevent AMS helps stimulate breathing and raises blood oxygen but can also increase urination, a consideration for individuals with on bladder involvement. Side effects of antispasmodics can be confusion, dizziness, and fatigue and may be confused with signs of AMS.

\section{DIAGNOSTICS}

Additional diagnostics beyond the preparticipation assessment of function and fitness may be needed in specific disabilities. Cervical spine films for Atlantooccipital instability in Down syndrome should be considered dependent on the event. Pulmonary function tests in restrictive lung disorder due to progressive muscular dystrophy can be helpful, especially in events involving considerable, prolonged endurance demands and altitude exposure. Echocardiogram and EKG need to be individually considered in congenital cardiac conditions, especially if the event's fitness requirements exceed what an athlete has completed in training.

Team assessment of wheelchair seat fit and prosthetic adjustments for optimal biomechanics in assistive devices are part of the initial PPE but may require further measurements and trial of systems to best accommodate the athlete. Seating considerations should address needs for (1) postural control, (2) pressure relief, and (3) comfort. ${ }^{56}$ Skin breakdown and ulcer risk factors include body type, nutritional level, presence of infection, age, sitting posture, transfer and handling abilities, and the microclimate (increased temperature and moisture at contact sites) at the buttock-seat or other skin-wheelchair interfaces. ${ }^{57}$ Attention to pressure relief is important-skin is prone to breakdown during changes in direction and with high amounts of lateral move- ment, ${ }^{56}$ and educating athletes regarding position shifts and weight distribution during activity (and at rest) is encouraged. Maintaining dry and clean skin in microclimates of equipment interface is part of the education process (wet skin is more likely damaged than dry skin), and assessing for moisture-absorbing cushion and clothing is important. ${ }^{56,57}$ Antibacterial creams or ointments and protective, hydrocolloid dressings should be available.

Functionality of specialized equipment may be affected by the environment. Maintenance, charging, and power sources for power wheelchair or adaptive terrain vehicles should be taken into consideration. Extreme temperatures reduce battery life. Portable chargers, car chargers, and some solar options exist for extended outdoor excursions. Chargers are countryspecific, if international travel is a consideration. Physicians should be aware that wheelchair batteries may be "wet-cell" or "gel-cell." " Wet-cell batteries last longer, are less expensive, and are more powerful for traversing obstacles. However, this type of battery contains water (subject to evaporation and spilling) and is not typically allowed on airlines. Gel batteries are considered maintenance free and safe on airlines but may not last as long on extended outings. ${ }^{56}$ 


\section{Summary}

Wilderness outdoor excursions and competitions are attainable for athletes with disabilities and special needs. Successful and safe events with good outcomes will encourage further outdoor activity participation. Both the PPE and an EAP begin with understanding the individual's needs and the event's potential risks. Consideration of the additional medications and mobility aids that are part of the athlete's basic daily functions in the presence of the potential environmental conditions, altitude, and terrain are key. Although all outdoor events and athletes with special needs or physical disability cannot be detailed here, an individualized plan is the best approach through a PPE that focuses on not just physical conditions but cognition, communication-both expression and comprehension-and the mobility aids. The types of medications, and equipment needed for bowel and bladder function, may require specific storage and sterile packaging. The mobility aids, such as power sources, seating systems, and different terminal devices for prosthetics, may need fabrication and planning before the event; occasionally a comparative overnight or practice run-through may best assess for any potential emergency or safety issues.

As a team member, coach or medical professional who is part of the athlete's team, these general recommendations can optimize a successful outcome.

\section{Female Athletes (Van Baak and Joy)}

\section{PREGNANT WOMEN}

\section{Living at High Altitude}

For pregnant women, high altitude becomes physiologically and clinically relevant at altitudes $\geq 2400 \mathrm{~m}$ ( $\sim 7900 \mathrm{ft})$. Higher rates of low-birth-weight babies are observed in high altitude states. ${ }^{58}$ For every $1000 \mathrm{~m}$ increase in maternal altitude exposure during pregnancy, there is an associated $75.9 \mathrm{~g}$ reduction in birth weight. ${ }^{59}$ Similarly, there is a higher incidence of preeclampsia among pregnant women living at higher altitude (3100 m). ${ }^{60}$ The normal pregnancy-associated fall in blood pressure is absent even in normotensive pregnant women living at high altitude. ${ }^{60}$

A number of other pregnancy-related complications are observed in women living at higher altitudes, including higher rates of bleeding in the first trimester, premature rupture of membranes, preterm labor, oligohydramnios, polyhydramnios, placental abruption, placenta previa, fetal and neonatal respiratory distress, nuchal cord, congenital abnormalities, early arterial desaturation, perinatal respiratory infections, increased peripheral vascular resistance, pulmonary hypertension, and perinatal mortality. ${ }^{58}$

\section{Visiting or Moving to High Altitude}

Pregnant women are not at increased risk of altitude- related illness; however, altitude may increase risk of other conditions, and travel to high altitude ( $>8000 \mathrm{ft}$ ) is contraindicated in the first trimester if women are felt to be at increased risk of spontaneous abortion (SAB). ${ }^{61}$ Additional contraindications to high altitude exposure are gestational hypertension, preeclampsia, intrauterine growth retardation, anemia, and maternal smoking. ${ }^{61}$ For otherwise healthy pregnant women, moderate physical exertion is reasonable after 2 to 3 days of acclimatization. ${ }^{61}$

Pregnant women traveling to on airplanes should travel in pressurized cabins in large planes, and if traveling in small planes, should fly at altitudes $<7000 \mathrm{ft}^{62}$ Most commercial airlines allow pregnant travelers to fly up until 36 weeks' gestation. Some airlines limit international travel earlier in pregnancy, and some require documentation of gestational age. Travelers should check with the airline to find out its specific requirements or guidance for pregnant women. ${ }^{63}$

\section{Exercise at Altitude}

The American College of Obstetricians and Gynecologists recommends that pregnant women limit exercise at altitude to $<1830 \mathrm{~m}(6000 \mathrm{ft}) .{ }^{64}$ The Society for Obstetrics and Gynecology (SCOG) in Canada found no evidence of adverse effects with moderate exercise at altitudes of 1800 to $2500 \mathrm{~m} .{ }^{64}$ The SCOG recommends that women take appropriate steps to acclimatize before exercise above $2500 \mathrm{~m} .{ }^{64}$ There is limited outcomes data for pregnant women with short-term exposure to exercise at higher altitudes during pregnancy; as such, it is generally recommended that exercise at altitude should be approached cautiously.

To prevent altitude sickness, it is advised that pregnant women should ascend slowly at altitudes $.2000 \mathrm{~m}$, increasing their sleeping altitude by no more than 300 to $500 \mathrm{~m}$ per day, ensuring adequate rest, with rest days every 3 to 4 days of trekking. ${ }^{65}$

There are limited data, and in most cases no data, addressing risks associated with specific adventure or wilderness sporting activities during pregnancy. Downhill and nordic skiing are activities enjoyed by many pregnant women. Based on conjecture and our understanding of both pregnancy and exercise physiology, there is probably no increased risk of SAB or placental abruption during the first trimester. However, as pregnancy progresses, pregnancy-associated weight gain and change in center of gravity might predispose women to falls, trauma, and subsequent placental disruption, 
especially in activities where balance is important. ${ }^{66}$ Women who desire to maintain their participation in rock climbing should consider the use of a special, possibly full body harness to avoid excessive abdominal pressure (Figure 2). Women should also be aware that pregnancy-related weight gain might predispose to finger- tendon injuries and strains associated with rock climbing.

Whether women are skiing, rock climbing, mountain climbing, or trekking, they need to do so after consulting with their obstetric care provider. Many physicians may recommend against these activities and the need for shared decisionmaking that carefully factors in known and unknown risks relative to events is paramount. The aforementioned recommendations largely apply to healthy women having healthy pregnancies. Although it is important to remember that pregnancy is a normal condition for women - and not a disease - the primary consideration is a healthy pregnancy outcome for mother

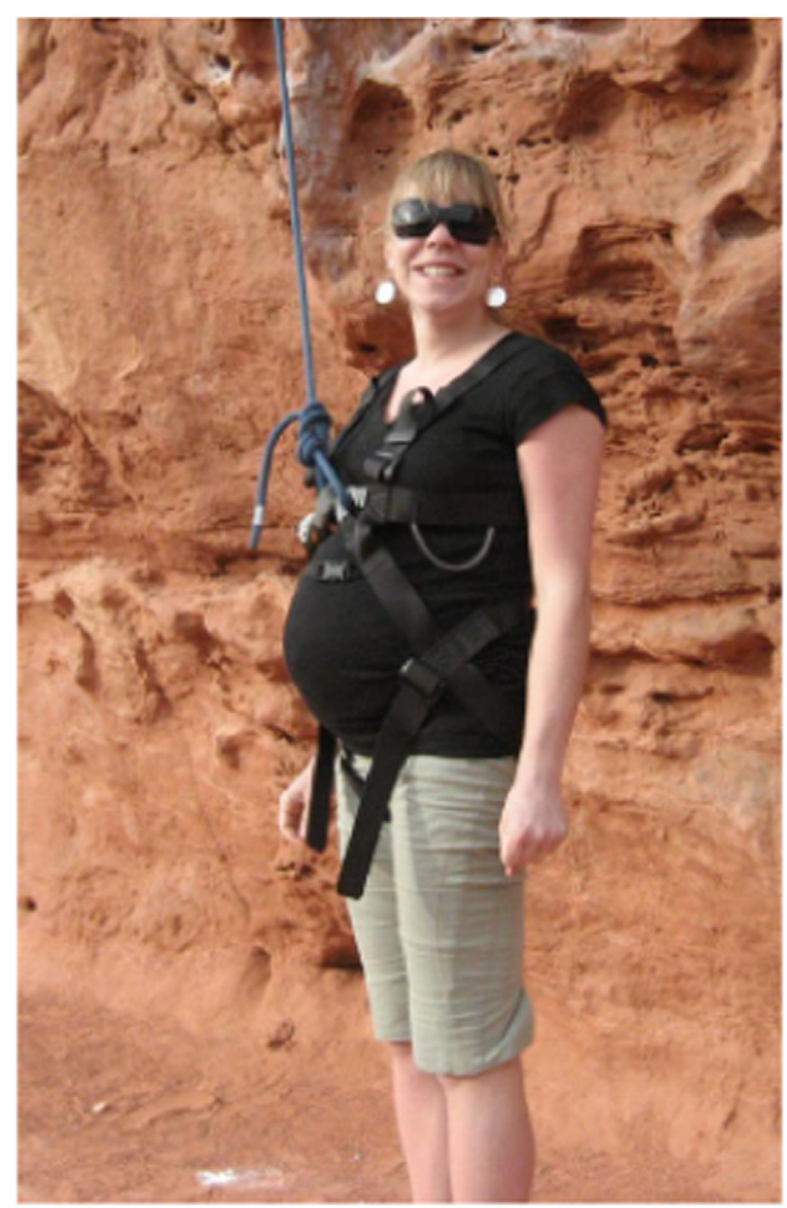

Figure 2. Rock climbing harness during pregnancy [Photo Credit John Evans (Utah)]. and baby. Higher risk activities should not be encouraged for the novices. Seasoned high-risk athletes should consider scaling back the intensity and exposure of their activities to minimize risk.

At the opposite end of the altitude continuum, scuba diving is not advised at any time during pregnancy regardless or experience or skill level because of the possibility of nitrogen air emboli crossing the placenta. ${ }^{67}$

\section{ENVENOMATIONS}

\section{Black Widow Spider Bites}

There are no outcome studies on the symptoms or severity of outcomes from black widow spider bites during pregnancy. In a study of 3194 women of childbearing age, 97 of whom were pregnant, no pregnancies were lost as a result of black widow spider bite. ${ }^{68}$

\section{Snake Bites}

The same cannot be said for snakebites. Of 213 venomous snakebites reported in the literature between 1966 and 2009 , the case fatality rate in pregnant females was $4 \%$, with a fetal loss rate of $20 \%{ }^{69}$ No maternal deaths were reported from North American species envenomation. This is thought to be related to better access to healthcare and antivenom in the United States and possibly less venomous snake species. ${ }^{69}$ A majority of snakebites are sustained by males $(73 \%$ vs $27 \%){ }^{70}$ Death from snakebite in the United States is uncommon, with a mortality rate of $<0.1 \% .^{7 \circ}$

Pregnant women should empirically avoid circumstances where envenomations are most likely to occur and seek medical care if they experience either a spider or snakebite.

\section{TRAVEL}

\section{Pretravel Counseling}

Obstetric care providers should focus on problems that might recur or progress, such as a history of miscarriage or ectopic pregnancy, and as a result of pregnancy, such as deep vein thrombosis, elevated blood pressure, and conditions specifically related to anticipated travel experience (eg, falls). Pregnant women should carry documentation of their due date and other important pregnancy history and risk factors. It is also important to discuss and counsel patients regarding the management of pregnancy symptoms such as nausea and vomiting in early pregnancy, and Braxton Hicks contractions in mid to late pregnancy. ${ }^{71}$ 
Table 3. Vaccination recommendations during pregnancy ${ }^{72}$

\begin{tabular}{|c|c|}
\hline $\begin{array}{l}\text { Recommended during } \\
\text { pregnancy }\end{array}$ & $\begin{array}{l}\text { Tdap (with each pregnancy } \\
\text { between } 27 \text { and } 36 \text { wk) } \\
\text { Influenza vaccine }\end{array}$ \\
\hline If indicated & $\begin{array}{l}\text { Meningococcal } \\
\text { Hepatitis A } \\
\text { Hepatitis B } \\
\text { Pneumococcal Polio } \\
\text { Postexposure rabies } \\
\text { vaccination }\end{array}$ \\
\hline $\begin{array}{l}\text { Only after careful consideration } \\
\text { of risks versus benefits }\end{array}$ & Yellow fever \\
\hline Contraindicated & $\begin{array}{l}\text { MMR } \\
\text { Varicella } \\
\text { Zoster }\end{array}$ \\
\hline $\begin{array}{l}\text { Limited or no data on vaccine } \\
\text { safety during pregnancy }\end{array}$ & $\begin{array}{l}\text { Typhoid } \\
\text { Japanese encephalitis }\end{array}$ \\
\hline
\end{tabular}

\section{INFECTIOUS DISEASE—VACCINATION}

A key strategy to prevent infectious disease during pregnancy is to receive recommended vaccinations. Table 3 outlines vaccination recommendations during pregnancy.

\section{INFECTIOUS DISEASE-INSECT REPELLENT}

N,N-diethyl-meta-toluamide (DEET) insect repellant applied in concentrations protective against malaria is considered safe and recommended in pregnancy based on controlled studies. There is no evidence that DEET applied during late pregnancy (second and third trimesters) poses a health hazard to the developing fetus. ${ }^{73,74}$ DEET crosses the placenta and the Centers for Disease Control (CDC) confers that the effects of DEET use in pregnancy have not been thoroughly studied, but the benefits of insect repellent use might outweigh any potential harm. To lower the risk of infections spread by mosquitoes, pregnant women should stay indoors during peak times of mosquito activity (usually dawn and dusk) and wear protective clothing. Pregnant women should apply insect repellent primarily to their clothing and, in small amounts, to exposed skin when necessary. ${ }^{75}$

\section{INFECTIOUS DISEASE-CHOLERA AND TRAVELER'S DIARRHEA}

Although not fully understood, traveler's diarrhea may be more prevalent in pregnant than nonpregnant travelers and is more likely to result in dehydration. ${ }^{76}$ Pregnant women traveling in endemic areas are recommended to practice strict hygiene, along with food and water precautions. Affected women should have vigorous oral hydration. Although loperamide is not recommended for prophylaxis, it is considered safe for treatment. ${ }^{77}$ Fluoroquinolones are not recommended for use during pregnancy, but azithromycin is considered safe for treatment of traveler's diarrhea when needed for severe symptoms, but many cases of mild traveler's diarrhea are selflimited and resolve with supporting measures. ${ }^{77}$ Rifaximin, although not absorbed systemically, does not have established safety during pregnancy. ${ }^{77}$ Although resistance to Cotrimox- azole or Bactrim is more likely, both are commonly used in pregnancy and are reasonable for the treatment of traveler' $\mathrm{s}$ diarrhea for those in whom azithromycin is contraindicated.

\section{INFECTIOUS DISEASE-MALARIA}

Pregnant women should be counseled to avoid travel to Malaria endemic areas or consider prophylaxis. $^{78}$ Mefloquine is the drug of choice for prophylaxis and therapy in pregnant women. If going to an area of high Mefloquine resistance, either Atovaquone-Proguanil or Artemether-Lumefantrine can be used. ${ }^{78}$ There is no good data on the safety of anti- malarials during the first trimester of pregnancy. ${ }^{78}$ Both doxy- cycline and primaquine are contraindicated anytime during pregnancy. ${ }^{79}$ For more information on medications for travel in pregnant women, refer to the $\mathrm{CDC}$ recommendations. ${ }^{63}$

\section{NONPREGNANT WOMEN}

\section{Specific Medical Issues}

Menses and Contraception. There is no difference between men and women with respect to the risk of developing $\mathrm{AMS}^{78,80}$ nor is the incidence of AMS affected by menstrual cycle phase. ${ }^{78}$ High altitude ascent may alter the menstrual cycle and it often occurs in conjunction with other factors, such as jet lag, intense exercise, cold exposure, and weight loss, which may be more important contributors. Menstrual changes were reported by $87 \%$ of female backpackers$41 \%$ of whom experienced shortened menstrual bleeding and $22 \%$ experienced amenorrhea. ${ }^{82}$ There are no data on the prevalence or incidence of the female athlete triad at altitude. Women should be counseled to ensure adequate dietary energy intake to reduce the likelihood of low energy availability, thereby increasing their risk of developing the triad. Because subclinical iron deficiency can impair acclimatization to very high altitude, iron supplementation is advised before an expedition for women with low ferritin levels, and ferritin levels should be maintained $>50 \mathrm{ng} / \mathrm{mL}^{81}$

The effectiveness of contraception is not affected by high altitude. ${ }^{66}$ However, irregular travel and sleep schedules may contribute to poor adherence with oral contraceptive regimens. Women might consider nonhormonal birth 
control or the Nu- vaRing if convenience of dosing and compliance are concerns. Combined oral contraceptive pills in combination with polycythemia, dehydration, and cold during long stays at high altitude could, in theory, increase the risk of thrombosis; however, there are no reported cases of deep vein thrombosis in this situation. ${ }^{66}$

\section{Sport-Specific Issues-Mountaineering and Winter Sports}

Men and women have similar odds of summiting and dying on Everest. ${ }^{83}$ Women should be counseled to use clothes and a harness that enables convenient urination and bowel movements. Some mountaineers recommend shaving their genital hair to facilitate hygiene in menstruating women. ${ }^{66}$

A survey of 353 winter backcountry users, asking them to rate avalanche danger, compared with avalanche danger estimation by Utah Avalanche Center found a nonsignificant trend for women to underestimate avalanche danger compared with men. ${ }^{84}$ Healthcare providers should inquire as to whether women participating in back country winter sports have undertaken the appropriate safety training.

\section{Summary}

Women participating in outdoor sports and activities are not at greater risk of injury or illness compared with men. Women of childbearing age should consider various options to manage menstruation and contraceptive needs. Pregnant women should consult with their obstetric care provider before embarking in activities such as skiing, rock climbing, mountain climbing, or trekking. Many physicians may recommend against these activities. Women and their obstetric care provider should engage in shared decision-making to carefully evaluate known and unknown risk factors related to desired activities and determine the safest course of action throughout pregnancy. The aforementioned recommendations largely apply to healthy women having healthy pregnancies. Although it is important to remember that pregnancy is a normal condition for women - and not a disease-the primary consideration is a healthy pregnancy outcome for mother and baby. Higher risk activities should not be encouraged for the novices. Seasoned high-risk athletes should consider scaling back the intensity and exposure of their activities to minimize risk.

\section{References}

1. American Academy of Family Physicians, American Academy of Pediatrics, American College of Sports
Medicine. Bernhardt D, Roberts W (Eds). Preparticipation Physical Evaluation, 4th ed. American Academy of Pediatrics, Elk Grove Village, IL 2010.

2. Niermeyer S. Cardiopulmonary transition in the high altitude infant. High Alt Med Biol. 2003;4:225-239.

3. Niermeyer S. Going to high altitude with a newborn infant. High Alt Med Biol. 2007;8:117-123.

4. Niermeyer S, Shaffer EM, Thilo E, et al. Arterial oxygenation and pulmonary arterial pressure in healthy neonates and infants at high altitude. J Pediatr. 1993;123: 767-772.

5. Alvaro R, Alvarez J, Kwiatkowski K, et al. Small preterm infants $(<1500 \mathrm{~g})$ have only a sustained decrease in ventilation in response to hypoxia. Pediatr Res. 1992;32: 403-406.

6. Wu TY, Miao C, Lin C, et al. Altitude illness in children on the Tibetan plateau. Progress in mountain medicine and high-altitude physiology. In: Ohno H, Kobayashi T, Masuyama S, et al, eds. 3rd World Congress on Mountain Medicine and High-Altitude Physiology. Matsumoto, Japan: Press Committee of the 3rd World Congress on Mountain Medicine and High Altitude Physiology; 1998:195-200.

7. Yaron M, Waldman N, Niermeyer S, et al. The diagnosis of acute mountain sickness in preverbal children. Arch Pediatr Adolesc Med. 1998;152:683-687.

8. Yaron M, Niermeyer S, Lindgren K, et al. Evaluation of diagnostic criteria and incidence of acute mountain sickness in preverbal children. Wilderness Environ Med. 2002;13:21-26.

9. Theis MK, Honigman B, Yip R, et al. Acute mountain sickness in children at 2835 meters. Am J Dis Child. 1993; 147:143-145.

10. Bloch J, Duplain H, Rimoldi SF, et al. Prevalence and time course of acute mountain sickness in older children and adolescents after rapid ascent to 3450 meters. Pediatrics. 2009;123:1-5.

11. Rexhaj E, Garcin S, Rimoldi SF, et al. Reproducibility of acute mountain sickness in children and adults: a prospective study. Pediatrics. 2011;127:e1445-e1448.

12. Moraga FA, Osorio JD, Vargas ME. Acute mountain sickness in tourists with children at Lake Chungara (4400 m) in northern Chile. Wilderness Environ Med. 2002;13:31-35.

13. Moraga FA, Pedreros CP, Rodriguez CE. Acute mountain sickness in children and their parents after rapid ascent to 3500 m (Putre, Chile). Wilderness Environ Med. 2008;19: 287-292.

14. Honigman B, Theis K, Yip R, et al. Adverse effects of moderate altitude on a tourist population (Abstract). In: Sutton JR, Coates G, Houston CS, eds. Hypoxia and Mountain Medicine Burlington, VT: Queen City Press; 1992.

15. Scoggin CH, Hyers TM, Reeves JT, et al. High-altitude pulmonary edema in the children and young adults of Leadville, Colorado. N Engl J Med. 1977;297:1269-1272. 
16. Hultgren HN, Marticorena E. High altitude pulmonary edema: epidemiologic observations in Peru. Chest. 1978;74:372-376.

17. Jean D. Acute mountain sickness in children at $5100 \mathrm{~m}$. In: Viscor G, Ricart de Mesones A, Leal C, eds. Health \& Height: Proceedings of the Vth World congress on Mountain Medicine and High Altitude Physiology. Barcelona, Spain: Universitat De Barcelona; 2002:287-290.

18. Pollard AJ, Niermeyer S, Barry P, et al. Children at high altitude: an international consensus statement by an ad hoc committee of the International Society for Mountain Medicine. High Alt Med Biol. 2001;2:389-403.

19. Moore LG. Altitude-aggravated illness: examples from pregnancy and prenatal life. Ann Emerg Med. 1987;16: 965-973.

20. Yaron M, Niermeyer S. Travel to high altitude with young children: an approach for clinicians. High Alt Med Biol. 2008;9:265-269.

21. Schneider M, Bernasch D, Weymann J, et al. Acute mountain sickness: influence of susceptibility, preexposure, and ascent rate. Med Sci Sports Exerc. 2002;34: 1886-1891.

22. MacInnis MJ, Koehle MS, Rupert JL. Evidence for a genetic basis for altitude illness: 2010 update. High Alt Med Biol. 2010;11:349-368.

23. Wilson MJ, Julian CG, Roach RC. Genomic analysis of high altitude adaptation: innovations and implications. Curr Sports Med Rep. 2011;10:59-61.

24. Luks AM, McIntosh SE, Grissom CK, et al. Wilderness Medical Society consensus guidelines for the prevention and treatment of acute altitude illness. Wilderness Environ Med. 2010;21:146-155.

25. Durmowicz AG, Noordeweir E, Nicholas R, et al. Inflammatory processes may predispose children to high-altitude pulmonary edema. J Pediatr. 1997;130:838-840.

26. Durmowicz AG. Pulmonary edema in 6 children with down syndrome during travel to moderate altitudes. Pediatrics. 2001;108:443-447.

27. Das BB, Wolfe RR, Chan KC, et al. High-altitude pulmonary edema in children with underlying cardiopulmonary disorders and pulmonary hypertension living at altitude. Arch Pediatr Adolesc Med. 2004;158:11701176.

28. Ivy DD. Echocardiographic evaluation of pulmonary hypertension. In: Valdes-Cruz LM, Cayre RO, eds. Echocardiographic Diagnosis of Congenital Heart Disease: An Embryologic and Anatomic Approach. Philadelphia, PA: Lippincott Williams \& Wilkins; 1999:537-547.

29. Claster S, Godwin MJ, Embury SH. Risk of altitude exposure in sickle cell disease. West J Med. 1981;135: 364-367.

30. Mahony BS, Githens JH. Sickling crises and altitude. Occurrence in the Colorado patient population. Clin Pediatr (Phila). 1979;18:431-438.

31. Roach RC, Bartsch P, Oelz O, et al. The Lake Louise acute mountain sickness scoring system. In: Sutton JR,
Houston G, Coates G, eds. Hypoxia and Molecular Medicine. Burlington, VT: Queen City Press; 1993:272-274.

32. Southard A, Niermeyer S, Yaron M. Language used in Lake Louise scoring system underestimates symptoms of acute mountain sickness in 4- to 11-year-old children. High Alt Med Biol. 2007;8:124-130.

33. Marticorena E, Hultgren HN. Evaluation of therapeutic methods in high altitude pulmonary edema. Am J Cardiol. 1979;43:307-312.

34. Swenson ER. Carbonic anhydrase inhibitors and hypoxic pulmonary vasoconstriction. Respir Physiol Neurobiol. 2006;151:209-216.

35. World Health Organization. Definition of an older or elderly person. Health statistics and health information systems. Web site: http://wwwwho.int/healthinfo/survey/ agingdefholer/en/index.html.

36. Center for Disease Control and Prevention. The State of Aging and Health in America (SAHA). Web site: http://www.cdc.gov/aging/help/dph-aging/state-aginghealth.html. Accessed June 14, 2015.

37. Erb RE. Predictors of success in wilderness ventures: physical activity, the environment and fatigue. Wilderness Med Lett. 1990;7:8.

38. Erb BD. Elderly in the wilderness: the gray eagles. Wilderness Med Lett. 1995;1:8.

39. Grissom C, Luks A, Deloughery T. Chronic Diseases and Wilderness Activities, in Auerbach P Wilderness Medicine. 6th ed. Philadelphia, PA: Elsevier; 2012:646.

40. Collins KJ, Abdel-Rahman TA, Goodwin J, et al. Cercadian body temperatures and the effects of cold stress in elderly and young subjects. Age Ageing. 1995;24:485.

41. Levine BD, Zuckerman JH, deFilippi CR. Effect of highaltitude exposure in the elderly: the tenth mountain division study. Circulation. 1997;96:1224.

42. Roach RC, Houston CS, Honigman B, et al. How well do older persons tolerate moderate altitude? West J Med. 1995; 162:32.

43. Honigman B, Theis MK, Kozial-McLain J, et al. Acute mountain sickness in a general tourist population at moderate altitudes. Ann Intern Med. 1993;118:587.

44. American College of Sports Medicine; American Academy of Family Physicians; American Academy of Orthopaedic Surgeons; American Medical Society for Sports Medicine; American Orthopaedic Society for Sports Medicine; American Osteopathic Academy of Sports Medicine, Team physician consensus statement: selected issues for the master athlete and the team physician: a consensus statement. Med Sci Sports Exerc. 2010;42:820 833.

45. Maron B, Araujo CG, Thompson PD, et al. Recommendations for preparticipation screening and assessment of cardiovascular disease in masters athletes. Circulation. 2001;103:327.

46. Baggish A, Levine B. Wilderness Cardiology. In: Auerbach P, ed. Wilderness Medicine. 6th ed. Philadelphia, PA: Elsevier; 2012:632. 
47. Vogel LA, Carotenuto G, Basti JJ, et al. Physical activity after total joint arthroplasty. Sports Health. 2011;3:441450.

48. Wu SK, Williams T. Factors influencing sport participation among athletes with spinal cord injury. Med Sci Sports Exerc. 2000;33:177-182.

49. Gonzalez EG, Corcoran PJ, Reyes RL. Energy expenditure in belowknee amputees: correlation with stump length. Arch Phys Med Rehabil. 1974;55:111-118.

50. Kitaoka Y. McArdle disease and exercise physiology. Biology (Basel). 2014;3:157-166.

51. Auerbach PS, ed. Wilderness Medicine. 6th ed. Philadelphia, PA: Elsevier, Mosby; 2012.

52. McKinley WO, Jackson AB, Cardena DD, et al. Longterm medical complications after traumatic spinal cord injury: a regional model systems analysis. Arch Phys Med Rehabil. 1999;80:1402-1410.

53. Mushett CA, Wyeth DO, Richter KJ. Cerebral palsy. In: Goldberg B, ed. Sports and Exercise for Children with Chronic Health Conditions. Champaign, IL: Human Kinetics; 1995:123-133.

54. Richter KJ. Seizures in athletes. J Osteopath Sports Med. 1989;3:19-23.

55. Nakken KO, Loyning A, Loyning $\mathrm{T}$, et al. Does physical exercise influence the occurrence of epileptiform EEG discharges in children? Epilepsia. 1997;38:279.

56. Cook AM, Polgar JM. Seating systems as enablers of function. In: Cook AM, Polgar M, eds. Essentials of Assistive Technologies. St. Louis MO: Elsevier Mosby; 2012:67-96.

57. Lai AM, Stanish WD, Stanish HI. The young athlete with physical challenges. Clin Sports Med. 2000;19:793-819.

58. Julian CG. High altitude during pregnancy. Clin Chest Med. 2011;32:21-31.

59. Zahran S, Breunig IM, Link BG, et al. A quasiexperimental analysis of maternal altitude exposure and infant birth weight. Am J Public Health. 2014;104(suppl 1): S166-S174.

60. Palmer SK, Moore LG, Young D, et al. Altered blood pressure course during normal pregnancy and increased preeclampsia at high altitude (3100 meters) in Colorado. Am J Obstet Gynecol. 1999;180:1161-1168.

61. Mieske K, Flaherty G, O’Brien T. Journeys to high altitude -risks and recommendations for travelers with preexisting medical conditions. J Trav Med. 2010;17:48-62.

62. Van Dyke P. A literature review of air medical work hazards and pregnancy. Air Med J. 2010;29:40-47.

63. Pregnant Travelers. Web site: http://wwwnc.cdc.gov/ travel/yellowbook/2014/chapter-8-nancyadvising-trave lers-with-specific-needs/pregnant-travelers. Accessed November 1, 2014.

64. Entin PL, Coffin L. Physiological basis for recommendations regarding exercise during pregnancy at high altitude. High Alt Med Biol. 2004;5:321-334.
65. Luks AM, Swenson ER. Medication and dosage considerations in the prophylaxis and treatment of high-altitude illness. Chest. 2008;133:744-755.

66. Jean D, Leal C, Kriemler S, et al. Medical recommendations for women going to altitude. High Alt Med Biol. 2005;6:22-31.

67. Camporesi EM. Diving and pregnancy. Semin Perinatol. 1996;20:292-302.

68. Wolfe MD, Myers O, Caravati EM, et al. Black widow spider envenomation in pregnancy. J Matern Fetal Neonatal Med. 2011;24:122-126.

69. Langley RL. Snakebite during pregnancy: a literature review. Wilderness Environ Med. 2010;21:54-60.

70. Seifert SA, Boyer LV, Benson BE, et al. AAPCC database characterizations of native US venomous snake exposures. Clin Toxicol (Phila). 2009;47:327-335.

71. Carroll ID, Van Gompel A. The pregnant wilderness traveler. Trav Med Infect Dis. 2005;3:225-238.

72. Guidelines for Vaccinating Pregnant Women. Web site: http://www.cdc.gov/vaccines/pubs/preg-guide. htm. Accessed October 25, 2014.

73. McGready R, Hamilton KA, Simpson JA, et al. Safety of the insect repellent $\mathrm{N}, \mathrm{N}$-diethyl-M-toluamide (DEET) in pregnancy. Am J Trop MedHyg. 2001;65:285-289.

74. Koren G, Matsui D, Bailey B. DEET-based insect repellants: safety implications for children and pregnant and lactating women. CMAJ. 2003;169:209-212.

75. Effects of Disasters on Pregnant Women: Environmental Exposures. Web site: http://www.cdc.gov/ncbddd/disas ters/environmental.html. Accessed December 28, 2014.

76. Samuel BU, Barry M. The pregnant traveler. Infect Dis Clin North Am. 1998;12:325-354.

77. Yates J. Traveler's diarrhea. Am Fam Physician. 2005;71: 2095-2100.

78. Roggelin L, Cramer JP. Malaria prevention in the pregnant traveller: a review. Travel Med Infect Dis. 2014;12:229-236.

79. Centers for Disease Control (U.S.), Advice for travelers. Treat Guidel Med Lett. 2009;7:83-94.

80. Maggiorini M, Buhler B, Walter M, et al. Prevalence of acute mountain sickness in the Swiss Alps. BMJ. 1990;301:853-855.

81. Sandoval D, Maes D, Lium D, et al. Women, exercise, and acute mountain sickness. In: Houston CS, Coates G, eds. Hypoxia. Women at Altitude. Burlington, VT: Queen City Printers; 1997:42-52.

82. Boulware DR. Gender differences among long distance backpackers: a prospective study of Women Appalachian Trail Backpackers. Wilderness Environ Med. 2004;15:175-180.

83. Huey RB, Salisbury R, Wang JL, et al. Effects of age and gender on success and death of mountaineers on Mount Everest. Biol Lett. 2007;3:498-500.

84. Richalet JP, Souberbielle JC, Antezana AM, et al. Control of erythropoiesis in humans during prolonged exposure to the altitude of $6542 \mathrm{~m}$. Am J Physiol. 1994;266:R756-R764. 